друга и могут только держаться собственных страха, совести, чувства, вины, воспоминания: «Мне бы скорее начать работать, чем придумывать хобби искать чего-то нового, поскорее впасть в эмоциональную кому, расписать свою жизнь на простые основы: любви не существует в природе - это раз, счастья в мире не бывает - это два, справедливости ты тут не найдешь - это три» [15].

1. Ухтомский А. А. Доминанта. СПб. : Питер, 2002. 448 с.

2. Бахтин М. М. Собрание сочинений. Т. 3: Теория романа (1930-1961 гг.). М. : Языки славянских культур, 2012. $880 \mathrm{c}$.

3. Кемеров В. Е. Социальный хронотоп как проблема интеграции современного обществознания // Научный ежегодник Института философии и права Уральского отделения Российской академии наук. 2007. Вып. 7. С. 109-114.

4. Азаренко С. А. Топологическое философрствование: тела, знаки и социальная коммуникация // Уральская философрская школа: 50 лет - 50 имен. Екатеринбург : Изд-во Уральского ин-та управления - филиала РАНХиГС, 2016. С. 147-159.

5. Березина Т. Н. Пространственно-временные особенности внутреннего мира личности : автореф. дис. ... д-ра психол. наук. М., 2003. 41 с.

6. Бахтин М. М. Творчество Франсуа Рабле и народная культура средневековья и Ренессанса // Собр. соч. Т. 4 (2): Творчество Франсуа Рабле и народная культура средневековья и Ренессанса (1965). Рабле и Гоголь (Искусство

УДК 130.122

Науч. спец. 09.00 .01

DOI: 10.36809/2309-9380-2020-28-44-48

\section{ОНТО-ГНОСЕОЛОГИЧЕСКОЕ ЗНАЧЕНИЕ ЛЮБВИ КАК ОДНОГО ИЗ ФОРМИРУЮЩИХ ОСНОВАНИЙ СУБЪЕКТА ПРАВА}

В статье исследуется онто-гносеологическое значение любви как основания, формирующего человека в его деятельности, в качестве примера взята правовая сфера. Ряд современных философов обнаруживают онтологическое и гносеологическое значение любви как способности человека обнаружить или обратить внимание на сущность другого, что выражается в уважении и признании другого. Кроме того, современные авторы на первый план выводят проблему ответственности субъекта за осознанное и рационально принятое решение о действии и высказывании субъекта. Ответственность связывается с такими способностями человека, как познание и любовь, что означает быть способным к рефрлексии и оценке себя как автора поступка или высказывания, а также любовь и уважение, неравнодушие в отношении другого.

Ключевые слова: бытие, право, любовь, познание, субъект права, субъект высказывания, субъект действия. слова и народная смеховая культура) $(1940,1970)$. Комментарии и приложение. М. : Языки славянских культур, 2010. С. 7-517.

7. Гиндин В. П. Психопатология в русской литературе. М. : ПЕР СЭ, 2012. 224 c.

8. Модестов Н. С. Маньяки. Слепая смерть. Хроника серийный убийств. URL: https://www.e-reading.club/ bookreader.php/39578/Modestov_-_Man\%27yaki_\%26_ Slepaya_smert\%27_Hronika_seriiinyh_ubiiistv.html (дата обращения: 29.05.2020).

9. Антонов С. П. Аленка. М. : Советская Россия, 1975.80 с.

10. Андрианова И. А. Мой сумасшедший папа. М. : Детская литература, 2016. 188 с.

11. Кивинов А. В. Умирать подано. СПб. : Нева ; М. : ОЛМА-ПРЕСС, 1999. 448 С.

12. Гайдар А. П. Дневники // Собр. соч. : в 4 т. М. : Государственное издательство детской литературы, 1960. Т. 4. C. 520-553.

13. Гайдар А. П. Судьба барабанщика. М. : Детская литература, 2007. $183 \mathrm{c}$.

14. Гайдар А. П. Клятва Тимура // Собр. соч. : в 4 т. М. : Государственное издательство детской литературы, 1956. Т. 3. С. 233-276.

15. Алехин Е., Михайлов С. Замри и умри. URL: https:// night-loaders.livejournal.com/2551.html\#cutid1 (дата обращения: 29.05.2020).

(C) Политов А. В., 2020

\title{
ONTO-GNOSEOLOGICAL SIGNIFICANCE OF LOVE AS ONE OF THE FORMING FOUNDATIONS OF THE SUBJECT OF LAW
}

The article examines the onto-gnoseological significance of love as the foundation that forms a person in his activities. The legal sphere is taken as an example. A number of modern philosophers discover the ontological and epistemological significance of love as the ability of a person to detect or pay attention to the essence of another, which is expressed in respect and recognition of the other. In addition, modern authors bring to the fore the problem of the subject's responsibility for a conscious and rationally made decision about the subject's action and expression. Responsibility is associated with such human abilities as knowledge and love, which means being able to reflect and evaluate oneself as the author of an act or statement, as well as love and respect, indifference towards another.

Keywords: entity, law, love, cognition, subject of law, subject of utterance, subject of action. 
Одна из ключевых особенностей философского анализа - системное исследование различных областей деятельности человека. В данной статье такой сферой деятельности человека будет выступать сфера права, в которой одна из центральных проблем - субъект права, его место и роль в системе права, способность человека взять ответственность за свои действия и их результаты. Субъект права рассматривается нами как многомерный феномен, в силу значимости права и правоотношений во всех сферах деятельности человека. Очевидными аспектами для изучения особенностей субъекта права становятся экономические, политические, социальные, психологические фракторы его развития. Однако не менее значимыми аспектами в изучении субъекта права являются способы присутствия субъекта права в разных сферах культуротворческой деятельности человека. Данная многомерность субъекта права выражается в многообразии подходов, исследующих данный феномен. Систематизировать различные особенности субъекта права, способы его присутствия в бытии в различных сфрерах деятельности способна теоретическая часть современной философии - онтология и теория познания.

В рамках онтологии вопросы, связанные с изучением субъекта права, могут быть сформулированы следующим образом: о праве на существование, о роли права в защите самой человеческой сущности, о свободе действия от собственного лица и возникающей при этом ответственности как за других, так и за бытие в целом. В контексте гносеологии как области философии вопросы, относящиеся к изучению субъекта права, связаны со значимостью правовой рефлексии, понимаемой как внутренний опыт осознания права и осознание своей ответственности, а также соотношение истины и правовой справедливости, осознание необходимости в праве и соотношения со свободой субъекта. Анализ специфики субъекта права актуален в силу разнообразия сфрормировавшихся трактовок человека, основывающихся в большей степени на особенностях практической деятельности человека, его целей в различных сфрерах общественной жизни. Обнаружение онто-гносеологических оснований человека как субъекта права позволит развивать правовую культуру и правовое мировоззрение, а также совершенствовать права человека. Проблема исследования человека, выступающего в роли субъекта права, связана с необходимостью совмещения онто-гносеологического осмысления бытия человека и практической составляющей его действий, поступков, речи, высказываний. Поскольку человек - часть бытия, его онтологический статус не может не оказывать влияния на все сферы человеческой жизни. В этом смысле в праве воплощаются сущностные силы человека.

Подтверждение этому мы находим в философско-правовом учении Г. В. Ф. Гегеля, в рамках которого осуществляется поиск онтологических оснований при изучении человеческой деятельности в любой сфере. Философ, описывая развитие явления, начинает с природной (материальной) ступени его проявления и движется к раскрытию наивысшей ступени, в которой проявляется духовное основание идея в качестве осуществленного понятия. Так, на примере права он показывает взаимосвязь идеального бытия права и практическую жизнь человека, в которой оно воплощается.
Сущность права, в понимании немецкого мыслителя, выражается через наполнение данного понятия идеей свободы: «Право... наличное бытие абсолютного понятия, самосознательной свободы» [1, с. 90]. В рамках практической деятельности человека сущность права воплощается в различных формах свободы. В единое целое эти формы объединяет субстанциальная воля, поскольку «...всякое наличное бытие есть право только на основе свободной субстанциальной воли...» [2, с. 327]. Человек своим существованием реализует идею права - свободу, стремясь актуализировать ее во всех сферах своей жизнедеятельности (социальной, экономической, политической, культурной, духовной), принимая участие в жизни семьи и государства. Возможность реализовать идею права (свободу) человек может благодаря тому, что право обнаруживает себя и в духовном бытии человека.

Поскольку любое явление рассматривается от природного или материального начала в развитии к духовному основанию, то в определении человека также обнаруживается природная и телесная составляющая, а также духовная. Человек отличается от того, что принадлежит только природным явлениям, тем, что он способен мыслить: «...значение познания того, что подлинно в человеке, подлинно в себе и для себя, - познания самой сущности как духа» [2, с. 6]. Благодаря мышлению человек преобразует душу в Дух, тем самым реализуется высшая способность Духа - разум. Непрерывная деятельность духа (познание как осознание себя и мира) приводят дух к его цели: «...его развитие достигает своей цели, если его понятие оказалось полностью осуществленным, или, что то же самое, если дух достиг полного сознания своего развития» [2, с. 12]. Тело человека и его дух связаны, поскольку помимо своей субстанциальной основы - свободы дух обладает деятельностной природой - влечением.

В учении Гегеля субъект - это деятель, осуществляющий перевод субъективного влечения в объективное состояние - долженствование. Долженствование, содержащееся в развитой воле, при развитии духа до своего абсолюта становится нравственностью. Так, задача духа заключается в обнаружении и сообщении содержанию влечения разумности и объективности. На данном этапе снимается природная составляющая влечения, влечение становится необходимым отношением, выраженным в правах и обязанностях: «Было бы абсурдом желать исключить мышление из нравственности, религиозности, области права и т. д.» [2, с. 312]. При помощи своего разума человек способен признать право, следовать правовым нормам, сознательно нести ответственность за свои поступки. По утверждению Гегеля, важность обретает цель и намерение, соответственно реализацию всеобщей цели - добра. «Субъективная воля требует, чтобы то, что пребывает внутри нее, т. е. ее цель, получило внешнее наличное бытие, чтобы, следовательно, добро совершалось во внешнем существовании» [1, с. 95]. Философ утверждает, что право становится наличным бытием свободной воли, получая свое выражение в обязанностях.

В своем философско-правовом учении Гегель находит аргументы для обоснования любви в качестве нравственного основания жизни. Он полагает, что благодаря чувству 
любви отдельные индивиды способны образовать единство в семье и государстве. Любовь находит свое воплощение в семье, выступая как нравственность природной формы, кроме того, семья имеет свое внешнее проявление в собственности, имуществе, расходах и проч. Именно семья аккумулирует и воплощает любовь (как нравственность природной формы), и собственность (как внешнее наличное бытие), и воспитание детей. Ведь любовь - такое осознание единства себя и другого, при котором я не являюсь изолированным ни для себя, ни для другого, а обретаю самосознание через отказ от полного обособления себя, зная себя посредством единения с другим и единством другого со мной. Следовательно, мораль и нравственность находят свое воплощение в семье, через мораль и нравственность право, как понятие, наполняется идеей свободы. Так, в сфере морали субъективная воля, выражающая себя через образ мыслей, намерений, умонастроений, становится субъективной обязанностью (характеризуется случайностью принятия решения). Тогда как в нравственной сфере обязанность и право достигают своего абсолютного единства, поскольку в сфере нравственности содержанием истинной свободы становятся общие интересы. По мысли Гегеля, нравственная личность пронизана субстанциальной жизнью - добродетелью, в том смысле, что в мышлении индивида есть «знание о субстанции и о тождестве всех их [индивидуумов] интересов с целым; и то, что другие единичные существа взаимно знают себя только в этом тождестве и действительно существуют в нем...» [2, с. 340]. Если духовность принадлежит самой сущности человека, то эта логика неизбежно подводит к связи права с духовным бытием человека. Отсюда Гегель делает вывод, что нравственное содержание поступка субъекта имманентно ему и должно быть осуществлено. Такое духовное определение пронизано доверием и любовью. Чем сильнее человек развивает в себе духовные способности, тем полнее дух наполняется своей субстанцией - свободой, тем более ценным становится содержание самого права. Так, понятие «любовь» в философско-правовом учении мыслителя приобретает большую значимость для формирования правовой жизни общества. Данный аспект раскрывает М. Шелер, в своих работах он определяет человека «как духовную сущность, подчиняющуюся новому порядку и новому единству, основанному на любви» [3, с. 386].

Философские идеи Гегеля о взаимосвязи бытия, человека и права на онтологическом уровне показывают, что право содержит в себе все атрибуты человеческого бытия, а в самом человеке есть основания, способные воспринять право и следовать ему. Любовь, рассматриваемая онтологически (выступающая как субстанциальный акт), дает возможность принять его, понять единство с другим, осознать право на самостоятельное существование другого.

Благодаря историко-философскому анализу понятия «любовь» мы обнаруживаем стремление связать данное понятие с деятельностью человека в различных сферах. Приведем несколько примеров. Так, в греческой философии термин «рhilia» (дружба) и «philos» (друг) используются в двух значениях. Наряду со значением друг, данный термин имеет значение, характеризующее принадлежность к группе лиц с определенными обязательствами. По мысли Э. Бенвениста, такая связь становится фундаментальной. Он приводит в пример статус и положение гостя, «приехавшего в страну, в которой как иностранец он лишен прав» [4, с. 224]. Гость может найти кров и быть в безопасности только у того, с кем он состоит в дружеских отношениях. Кроме того, необходимо материальное подтверждение «приятия» в договоре между друзьями - «philotes» или в клятве - «philoi». В этом отношении «philia» получает значение обязательства перед своим гостем - другом.

Для средневековой философской традиции характерно онтологическое понимание любви как субстанциального акта, имеющего опору в объекте, иными словами переходящего от субъекта на объект. Онтологическое толкование понятия любовь обосновывается через Открытость сердца Богу и «ожидание Его активного Откровения» [5, с. 84].

Любовь как руководящий принцип или начало гражданского общежития встречается в философско-правовых работах Г. Гроция и X. Томазия. Так, Х. Томазий, будучи юристом и философом, указывал, что благожелательные чувства, связанные со стремлением к общению с другими, превалируют в человеке. Исток такого понимания любви П. И. Новгородцев видит в философско-правовом учении Г. Гроция, который признавал прирожденный альтруистический инстинкт - стремление к общежитию, в котором любовь становится центром личной и общественной жизни [6, с. 105]. Хоть в новоевропейской философии акцент ставится на исследовании роли разума и познавательной деятельности человека во всех сферах его жизни, разрабатывая принцип рационального устройства жизни общества, О. Конт в работе «Общий обзор позитивизма» указывает, что основным условием прогресса является порядок, в то время как принципом, на котором выстраивается общественный порядок, является любовь [7, с. 143]. Любовь становится принципом, который формирует рациональный образ жизни новейшей цивилизации.

В современной философии осмысление понятия любви в рамках философии права встречается не часто. Более того, как утверждает П. Рикёр, правовая проблематика не рассматривается в рамках философрских концепций, философы оставили разработку правовых проблем юридической науке, поскольку область исследования права стала самостоятельной областью знания - «право стало позитивной наукой» [8, с. 27]. Однако и сама философия претерпела изменения. Как отмечает М. Фуко в работе «Слова и вещи», в начале XIX в. изменяется связь между мышлением субъекта и бытием. Взаимосвязь между бытием и познанием опосредована языком. Отсюда возникает «...стремление сделать научный язык нейтральным... очистить от неподобающих случайностей... ради того, чтобы язык мог стать точным отражением... внесловесного познания» [9, с. 320-321]. Что касается исследования субъекта права, то подобное стремление очистить язык от «неточностей» и попытка сделать его «научным», показала, что в определении субъекта права в рамках философских исследований были вынесены за скобки определения духовных оснований человека. Определение структур духовности приводят к идеологизированной духовности, которая «имеет прямое отношение к требова- 
нию формирования субъекта... но мыслится в социальных понятиях, в организационных терминах» [10, с. 44]. Показателен пример юридического позитивизма, определяющего субъекта только с помощью нормативных характеристик, т. е. как участника правовых отношений, или представители современных направлений философии права Г. Харт и Р. Нозик, обращающиеся к изучению субъекта права для того, чтобы выявить механизм действий человека, выступающего субъектом права, а также найти принципы для развития прав человека. Для решения поставленных задач в определение субъекта права они вводят такие понятия, как агент и актор. Следует упомянуть, что в исследовательской литературе термины «агент» и «актор» появляются в 1970-е гг. Так, Т. Парсонс дает следующее определение: «Актор - это эмпирическая система действия... индивид или коллектив, которые могут быть взяты за точку отсчета при анализе способов их ориентирования и осуществления действия по отношению к объектам» [11, с. 463]. Кроме того, актор это тот, кто «способен взять ответственность за свои действия и их результаты, поскольку эти действия и результаты определяются волей свободного и рационального существа» (здесь и далее перевод наш. - М. П.) [12, р. 9]. Подчеркнем значимость данного определения, поскольку в нем фиксируется способность субъекта рационально определить результаты своих действий.

Тем не менее в работах современных философров А. Хоннета, Э. Фромма, П. Рикёра, Х. Арендт, Ж. Деррида и др. можно обнаружить осмысление человека как ценности в отношении к другому, а исполнение им должного (своих обязанностей) описывается способностью неравнодушного отношения к другому, т. е. любовью, понимаемой как стремление поддержать, взрастить его свободу и его индивидуальность. На первый план выводится проблема ответственности субъекта за осознанное действие и высказывание. Э. Фромм в работе «Человек для самого себя» предложил рассматривать продуктивное отношение к миру и другим людям, выражающееся в действия, поступках, понимании и умозрении. Человек может постичь мир с помощью деятельности разума и любви: «Сила разума позволяет ему проникать в суть вещей и явлений... Сила его любви позволяет ему преодолеть преграду, отделяющую его от другого человека, чтобы лучше понять его» [13, с. 116]. Важно отметить, что философы продолжают вслед за классиками относить к числу форм любви заботу, ответственность, уважение и знание. Сущность любви, пишет Фромм, - это деятельность ради улучшения становления и развития другого. Любовь проявляется в заботе и ответственности не только за физическое благополучие, но и за стремление развиваться духовно, творчески. Уважение и знание связано со способностью «...видеть человека таким, как он есть, в своей индивидуальности и неповторимости» [13, с. 120-121]. Здесь значимым аспектом становится умение не искажать индивидуальность человека, его природу, а также видеть взаимосвязь с другими явлениями, которые его окружают, иными словами, целостно воспринимать другого.

Философы в своих работах раскрывают онтологическую обусловленность действия и высказывания человека, рассматривая их как атрибуты субъекта права. Дело в том, что действие и речь обладают онтологической возможностью нового начала. Через речь и действие человек встраивается в общественные отношения, но, кроме этого, осознавая свои поступки и высказывания, человек выступает-в-явленность бытия. Иными словами, обнаруживает себя и предстает тем, кем он является: выступив-в-явленность человек обозначает свою сущность, а посредством речи человек идентифицирует себя (см. об этом: [14, с. 228-237]). Отметим, что благодаря данным способностям человек следует нормам права. Вопрос, при каком условии субъект совершит то или иное действие, заменяется вопросом, кто этот субъект, бытие которого заключается в процессуальной или другой деятельности (гражданско-правовой).

Ж. Деррида отмечает в своих работах, что проблема определения субъекта права и его статуса останавливается на определении субъекта через вещи, которые его окружают. Происходит постепенное овеществление Я: вещи «...переносят на него [субъекта] их основной атрибут» [15, с. 187] Философр видит решение в построении определения субъекта через его действия, а также в анализе субъекта действия в языковой среде. «Для Деррида язык всегда выступает как механизм, который не центрируется на Я, на самости (ipse) и не может быть присвоен никаким субъектом» [16, c. 372]. Ж. Деррида пытается выяснить: кто является обладателем прав - человек или гражданин? Он замечает, что нормы права действуют на определенной территории и имеют локальное значение, что означает внешнее закрепление прав и обязанностей человека государством, городом и др. В этом смысле как таковой человек оказывается лишенным прав, ведь сама идея о том, что человеку даны права от рождения, провозглашается суверенным государством. Развивая эту идею дальше, он замечает: «Больше того, принадлежность к роду человеческому не обладает юридической силой» [16, с. 217]. Ж. Деррида подчеркивает, что для европейской культуры была характерна ситуация, при которой не зависимо от юридического и гражданского статуса человек получал свои права. Резонно задать вопрос, что это за сила, которая способна наделить человека правами и обязанностями, если мы исключаем юридическую силу? По его словам, этой силой становится философия, поскольку одной из задач философии было определение прав и свобод человека, его статуса, обоснование свободы, истины, справедливости вне зависимости от государственного решения, идеологии или нравоучения. Так, французский философ трансформирует вопрос о субъекте права и его статусе на вопрос о неотчуждаемости права человека на философию. Анализируя правовую сферу, он показывает, что закон, выстроенный на позитивных структурах опыта, подвержен деконструкции. Деконструкция, как процесс пересмотра и улучшения закона, стремится к выражению справедливости, которая не деконструируется «ведь она не есть ни сущность, ни порядок, ни реальность, ни идеал» [16, с. 271]. Деконструкция находится на границе между справедливостью и законом и представляет собой край или предел, формирующийся областью позитивного права и справедливостью. «Справедливость - опыт абсолютной инаковости, она не ограничивается миром юридического или политического опыта» $[17$, р. 25]. Справедливость определяется как то, что дает 


\section{ФИЛОСОФИЯ}

импульс совершенствования закона - его деконструкцию. Для Ж. Деррида деконструкция не является стратегией субъекта. Под деконструкцией он понимает мотив будущего или событие будущего, то, чем предстанет закон или каким он будет после деконструкции. Деконструкция призывает нас к безграничной ответственности [18, р. 221].

Единство бытия и человека обеспечивается в том числе правилами поведения и законами, поскольку содержат в своем основании предназначение: «...чтобы человек нашелся в истине бытия как своем местопребывании» $[19$, с. 218]. Для нашего рассуждения значимо то, что способность человека проявить свою сущность - экзистировать в истине бытия - выражается в обнаружении правила, предназначенного истиной бытия. Следовательно, обнаружить свою соразмерность со-бытию в поддержании порядка и выполнении обязательств. М. Хайдеггер показывает, что ответственность человека заключается в решимости обратиться к своей совести и истолковать ее призыв к подлинному существованию. Именно совесть, как утверждает философ, тот френомен, который позволяет «развернуться к онтологическому устройству этого сущего» [20, с. 279]. Подлинное существование - это выбор человеком себя (осознанного действия и высказывания, соответствующего велению совести). Не подлинное существование или существование в самозабвение - это проявление пассивности и позволение другим определять себя в своем бытии. Данная проблематика становится областью аналитики бытия. В результате осознания своего действия или высказывания и способности обратиться к своей сущности проявляется соединение онтологического уровня существования со сфрерой практической жизни человека как субъекта права и в правовой сфере бытия человека.

Для неклассической фрилософии обращение к теме ответственности становится ключевым при анализе действий и высказываний человека. Ответственность связана с такими способностями человека, как познание и любовь, что означает быть способным к рефлексии и оценке себя как автора поступка или высказывания, а также любовь и уважение, неравнодушие в отношении другого. Подобный ракурс исследования права и субъекта права позволяет раскрыть право как способ человеческого бытия, который познается через осознание смысла бытия человека как целого, а его правового бытия как частного проявления.

1. Гегель Г.В.Ф.Философия права. М. : Мысль, 1990. $526 \mathrm{c}$.

2. Гегель Г.В.Ф.Энциклопедия философских наук. Т. 3 , Философия духа / отв. ред. Е. П. Ситковский. М. : Мысль, 1977. $471 \mathrm{c}$.
3. Шелер M. ORDO AMORIS // Избранные произведения. М. : Гнозис, 1994. С. 341-377.

4. Бенвенист Э. Глава 4. Philos // Бенвенист Э. Словарь индоевропейских социальных терминов / пер. с фр. ; общ. ред. Ю. С. Степанова. М. : Прогресс-Универс, 1995. С. 220-232.

5. Флоренский П. А. Столп и утверждение истины Т. 1 (1). М. : Правда, 1990. 492 с.

6. Новгородцев П. И. Лекции по истории философии права. Учение нового времени XVI-XIX вв. 4-е изд., испр. М. : Высшая школа, 1918. 209 с.

7. Конт О. Общий обзор позитивизма / под ред. Э. Л. Радлова ; пер. с фр. И. А. Шапиро. 3-е. изд. М. : ЛИБРОКОМ, 2012. 296 c.

8. Рикёр П. Торжество языка над насилием. Герменевтический подход к философии права // Вопросы философии. 1996. № 4. С. 27-36.

9. Фуко М. Слова и вещи. Археология гуманитарных наук / пер. с фр. ; вступ. ст. Н. С. Автономовой. М. : Прогресс, 1977. 488 с.

10. Фуко М. Герменевтика субъекта: Курс лекций, прочитанных в Коллеж де Франс в 1981-1982 учебном году / пер. с фрр. А. Г. Погоняйло. СПб. : Наука, 2007. 677 с.

11. Парсонс Т. О структуре социального действия. 2-е изд. М. : Академический Проект, 2002. 880 c.

12. Santoro E. Autonomy, Freedom and Rights. A Critique of Liberal Subjectivity. Netherlands : Springer, 2003. 294 p.

13. Фромм Э. Человек для самого себя / пер. с англ. Э. Спировой. М. : АСТ : АСТ МОСКВА, 2010. 350 с.

14. Арендт X. Vita activa, или О деятельной жизни / пер. с нем. и англ. В. В. Бибихина ; под ред. Д. М. Носова. СПб. : Алетейя, 2000. 437 с.

15. Гоноцкая Н. В. Охота за субъектом: подозрительный/подозреваемый субъект // Вопросы философии. 2015. № 2. С. 186-195.

16. Автономова Н. С. Философский язык Жака Деррида. М. : РОССПЭН, 2011. 512 C.

17. Patton P., Protevi J. Chapter 1: Future Politics // Between Deleuze and Derrida. London ; New York : Continuum, 2003. $207 p$.

18. Mikics D. Who Was Jacques Derrida?: an Intellectual Biography. New Haven \& London : Yale University Press, 2009. 296 p.

19. Хайдеггер М. Письмо о гуманизме / пер. с нем. // Хайдеггер М. Время и бытие: Статьи и выступления. М. : Республика, 1993. С. 192-220.

20. Хайдеггер М. Бытие и время / пер. с нем. В. В. Бибихина. М. : Ad Marginem, 1997. 452 c.

(C) Пырина М. В., 2020 